Annals of Pure and Applied Mathematics

Vol. 13, No. 1, 2017, 73-87

ISSN: 2279-087X (P), 2279-0888(online)

Published on 16 February 2017

www.researchmathsci.org

DOI: http://dx.doi.org/10.22457/apam.v13n1a8

Annals of

Pure and Applied Mathematics

\title{
On Edge Trimagic Labeling of Umbrella, Dumb Bell and Circular Ladder Graphs
}

\section{Jayasekaran ${ }^{1}$ and J. Little Flower ${ }^{2}$}

${ }^{1}$ Department of Mathematics, Pioneer Kumaraswamy College, Nagercoil - 629003

Tamilnadu, India. Email: jaya_pkc@yahoo.com

${ }^{2}$ Department of Mathematics, Arignar Anna College, Aralvaimozhy - 629301

Tamilnadu, India. Corresponding author. Email: littleflowerj.levin@yahoo.com

Received 2 January 2017; accepted 10 February 2017

Abstract. An edge trimagic total labeling of a graph $\mathrm{G}=(\mathrm{V}, \mathrm{E})$ with $\mathrm{p}$ vertices and $\mathrm{q}$ edges is a bijection $f: V(G) \cup E(G) \rightarrow\{1,2, \ldots, p+q\}$ such that for each edge $u v \in$ $E(G)$, the value of $f(u)+f(u v)+f(v)$ is either $k_{1}$ or $k_{2}$ or $k_{3}$. In this paper, we prove that the edge trimagic total labeling of Umbrella, Dumb bell and Circular ladder graphs.

Keywords: Graph labeling, Bijective function, Umbrella, Dumb bell, Circular ladder, Edge Trimagic.

\section{AMS Mathematics Subject Classification (2010): 05 C72}

\section{Introduction}

Graph labeling was first introduced in the mid sixties. A labeling of a graph is a map of integers to vertices or sometimes edges in a graph based upon certain criteria. In this paper the domain will be the set of all vertices and edges and such labeling are called total labeling [12]. Graph labeling are of many types such as graceful, harmonious, elegant, cordial magic, antimagic, bimagic, etc. This paper is an attempt to study of edge Trimagic total labeling. Harary [4] is referred to know about the notations in graph theory.

Magic labeling was introduced by Sedlacek [11]. Kotzing and Rosa [9], defined edge magic of a graph $\mathrm{G}$ with a bijection $\mathrm{f}: \mathrm{V} \cup \mathrm{E} \rightarrow\{1,2, \ldots, \mathrm{p}+\mathrm{q}\}$ such that, for each edge $u v \in E(G), f(u)+f(u v)+f(v)$ is a magic constant. In [3] shows the cycle $C_{n}$ with $P_{3}$ chords are edge magic total labeling. Edge bimagic labeling of graphs was introduced by Babujee [2] in 2004, defined by a graph $G$ with a bijection $f: V \cup E \rightarrow\{1,2, \ldots, p+q\}$ such that for each edge $u v \in E(G)$, the value of $f(u)+f(u v)+f(v)$ is either $k_{1}$ or $k_{2}$. Magic and bimagic labeling for disconnected graphs are showed in [1].

In 2013, Jayasekaran et al. [6] introduced the edge trimagic total labeling of graphs. An edge trimagic total labeling of a $(p, q)$ graph $G$ is a bijection $f: V \cup E \rightarrow\{1,2, \ldots, p+$ q) such that for each edge $u v \in E(G)$, the value of $f(u)+f(u v)+f(v)$ is equal to any of the distinct constants $\mathrm{k}_{1}$ or $\mathrm{k}_{2}$ or $\mathrm{k}_{3}$. An edge trimagic total labeling is called a super edge 


\section{C.Jayasekaran and J.Little Flower}

trimagic total labeling of a graph $\mathrm{G}$, if the vertices are labeled with the smallest possible integers i.e. $1,2, \ldots$, p. In [7], edge trimagic labeling of digraphs were discussed.

The graph $F_{n}=P_{n}+K_{1}$ is called a fan [10] where $P_{n}: u_{1} u_{2} \ldots u_{n}$ be a path and $V\left(K_{1}\right)=$ $\mathrm{u}$. The umbrella [10] $\mathrm{U}_{\mathrm{n}, \mathrm{m}}, \mathrm{m}>1$ is obtained from a fan $F_{n}$ by passing the end vertex of the path $\mathrm{P}_{\mathrm{m}}: \mathrm{v}_{1} \mathrm{v}_{2} \ldots \mathrm{v}_{\mathrm{m}}$ to the vertex of $\mathrm{K}_{1}$ of the fan $\mathrm{F}_{\mathrm{n}}$. The graph obtained by joining two disjoint cycles $u_{1} u_{2} \ldots u_{n} u_{1}$ and $v_{1} v_{2} \ldots v_{n} v_{1}$ with an edge $u_{1} v_{1}$ is called dumbbell [10] graph $\mathrm{Db}_{\mathrm{n}}$. A circular ladder [5] CL(n) is the union of an outer cycle $\mathrm{C}_{0}: \mathrm{u}_{1} \mathrm{u}_{2} \mathrm{u}_{3} \ldots \mathrm{u}_{\mathrm{n}} \mathrm{u}_{1}$ and an inner cycle $C_{1}: v_{1} v_{2} v_{3} \ldots v_{n} v_{1}$ with additional edges $\left(u_{i} v_{i}\right), i=1,2,3, \ldots$, n called spokes.

For more references, we use dynamic survey of graph labeling by Gallian [8]. In this paper, we prove that the graphs such as umbrella, dumb bell and circular ladder are edge trimagic and super edge trimagic labeling.

\section{Main results}

Theorem 2.1. The Umbrella $U_{n, m}$ is an edge trimagic total labeling for all $n$.

Proof: Let $\mathrm{V}=\left\{\mathrm{u}_{\mathrm{i}}, \mathrm{v}_{\mathrm{j}} / 1 \leq \mathrm{i} \leq \mathrm{n}, 1 \leq \mathrm{j} \leq \mathrm{m}\right\}$ be the vertex set and $\mathrm{E}=\left\{\mathrm{u}_{\mathrm{i}} \mathrm{u}_{\mathrm{i}+1}, \mathrm{v}_{\mathrm{j}} \mathrm{v}_{\mathrm{j}+1} / 1 \leq \mathrm{i}\right.$ $\leq \mathrm{n}-1,1 \leq \mathrm{j} \leq \mathrm{m}-1\} \cup\left\{\mathrm{v}_{1} \mathrm{u}_{\mathrm{i}} / 1 \leq \mathrm{i} \leq \mathrm{n}\right\}$ be the edge set of the graph $\mathrm{U}_{\mathrm{n}, \mathrm{m}}$. Then $\mathrm{U}_{\mathrm{n}, \mathrm{m}}$ has $n+m$ vertices and $2 n+m-2$ edges.

Case 1 . Both $\mathrm{n}$ and $\mathrm{m}$ are odd

Define a bijection $\mathrm{f}: \mathrm{V} \cup \mathrm{E} \rightarrow\{1,2, \ldots, 3 \mathrm{n}+2 \mathrm{~m}-2\}$ such that

$f\left(u_{i}\right)=\left\{\begin{array}{l}m+\frac{i+1}{2}, 1 \leq \mathrm{i} \leq \mathrm{n} \text { and } \mathrm{i} \text { is odd } \\ \mathrm{m}+\frac{\mathrm{n}+\mathrm{i}+1}{2}, 1 \leq \mathrm{i} \leq \mathrm{n} \text { and } \mathrm{i} \text { is even }\end{array}\right.$

$f\left(v_{j}\right)=\left\{\begin{array}{l}\frac{j+1}{2}, 1 \leq j \leq m \text { and } j \text { is odd } \\ \frac{m+j+1}{2}, 1 \leq j \leq m \text { and } j \text { is even }\end{array}\right.$

$\mathrm{f}\left(\mathrm{u}_{\mathrm{i}} \mathrm{u}_{\mathrm{i}+1}\right)=3 \mathrm{n}+\mathrm{m}-\mathrm{i}, 1 \leq \mathrm{i} \leq \mathrm{n}-1 ; \mathrm{f}\left(\mathrm{v}_{\mathrm{j}} \mathrm{v}_{\mathrm{j}+1}\right)=3 \mathrm{n}+2 \mathrm{~m}-\mathrm{j}-1,1 \leq \mathrm{j} \leq \mathrm{m}-1$ and

$f\left(v_{1} u_{i}\right)=\left\{\begin{array}{l}2 n+m+1-\frac{i+1}{2}, i \text { is odd } \\ n+m+\frac{n-i+1}{2}, i \text { is even }\end{array}\right.$

To prove this labeling is an edge trimagic total labeling.

Consider the edges $\mathrm{v}_{1} \mathrm{u}_{\mathrm{i}}, 1 \leq \mathrm{i} \leq \mathrm{n}$.

For odd $i, f\left(v_{1}\right)+f\left(v_{1} u_{i}\right)+f\left(u_{i}\right)=1+2 n+m+1-\frac{i+1}{2}+m+\frac{i+1}{2}=2 n+2 m+2=\lambda_{1}$.

For even $\mathrm{i}, \mathrm{f}\left(\mathrm{v}_{1}\right)+\mathrm{f}\left(\mathrm{v}_{1} \mathrm{u}_{\mathrm{i}}\right)+\mathrm{f}\left(\mathrm{u}_{\mathrm{i}}\right)=1+\mathrm{n}+\mathrm{m}+\frac{\mathrm{n}-\mathrm{i}+1}{2}+\mathrm{m}+\frac{\mathrm{n}+\mathrm{i}+1}{2}=2 \mathrm{n}+2 \mathrm{~m}+2=\lambda_{1}$.

Consider the edges $\mathrm{u}_{\mathrm{i}} \mathrm{u}_{\mathrm{i}+1}, 1 \leq \mathrm{i} \leq \mathrm{n}-1$. 
On Edge Trimagic Labeling of Umbrella, Dumb Bell and Circular Ladder Graphs

For odd $i, f\left(u_{i}\right)+f\left(u_{i} u_{i+1}\right)+f\left(u_{i+1}\right)=m+\frac{i+1}{2}+3 n+m-i+m+\frac{n+i+2}{2}=\frac{7 n+6 m+3}{2}=\lambda_{2}$.

For even $i, f\left(u_{i}\right)+f\left(u_{i} u_{i+1}\right)+f\left(u_{i+1}\right)=m+\frac{n+i+1}{2}+3 n+m-i+m+\frac{i+2}{2}=\frac{7 n+6 m+3}{2}=\lambda_{2}$.

Consider the edges $\mathrm{v}_{\mathrm{j}} \mathrm{v}_{\mathrm{j}+1}, 1 \leq \mathrm{j} \leq \mathrm{m}-1$.

For odd $j, f\left(v_{j}\right)+f\left(v_{j} v_{j+1}\right)+f\left(v_{j+1}\right)=\frac{j+1}{2}+3 n+2 m-j-1+\frac{m+j+2}{2}=\frac{6 n+5 m+1}{2}=\lambda_{3}$.

For even $\mathrm{j}, \mathrm{f}\left(\mathrm{v}_{\mathrm{j}}\right)+\mathrm{f}\left(\mathrm{v}_{\mathrm{j}} \mathrm{v}_{\mathrm{j}+1}\right)+\mathrm{f}\left(\mathrm{v}_{\mathrm{j}+1}\right)=\frac{\mathrm{m}+\mathrm{j}+1}{2}+3 \mathrm{n}+2 \mathrm{~m}-\mathrm{j}-1+\frac{\mathrm{j}+2}{2}=\frac{6 \mathrm{n}+5 \mathrm{~m}+1}{2}=\lambda_{3}$.

Hence for edge $u v \in E, f(u)+f(u v)+f(v)$ yields any one of the magic constants $\lambda_{1}=$ $2 n+2 m+2, \lambda_{2}=\frac{7 n+6 m+3}{2}$ and $\lambda_{3}=\frac{6 n+5 m+1}{2}$. Therefore the umbrella $U_{n, m}$ is an edge trimagic for both odd $\mathrm{n}$ and $\mathrm{m}$.

Case 2. $\mathrm{n}$ is odd and $\mathrm{m}$ is even

Define a bijection $\mathrm{f}: \mathrm{V} \cup \mathrm{E} \rightarrow\{1,2, \ldots, 3 \mathrm{n}+2 \mathrm{~m}-2\}$ such that

$f\left(u_{i}\right)=\left\{\begin{array}{l}m+\frac{i+1}{2}, 1 \leq \mathrm{i} \leq \mathrm{n} \text { and } \mathrm{i} \text { is odd } \\ \mathrm{m}+\frac{\mathrm{n}+\mathrm{i}+1}{2}, 1 \leq \mathrm{i} \leq \mathrm{n} \text { and } \mathrm{i} \text { is even }\end{array}\right.$

$f\left(v_{j}\right)=\left\{\begin{array}{l}\frac{j+1}{2}, 1 \leq j \leq m \text { and } j \text { is odd } \\ \frac{m+j}{2}, 1 \leq j \leq m \text { and } j \text { is even }\end{array}\right.$

$\mathrm{f}\left(\mathrm{u}_{\mathrm{i}} \mathrm{u}_{\mathrm{i}+1}\right)=3 \mathrm{n}+\mathrm{m}-\mathrm{i}, 1 \leq \mathrm{i} \leq \mathrm{n}-1 ; \mathrm{f}\left(\mathrm{v}_{\mathrm{j}} \mathrm{v}_{\mathrm{j}+1}\right)=3 \mathrm{n}+2 \mathrm{~m}-\mathrm{j}-1,1 \leq \mathrm{j} \leq \mathrm{m}-1$ and

$f\left(v_{1} u_{i}\right)=\left\{\begin{array}{l}2 n+m+1-\frac{i+1}{2}, 1 \leq i \leq n \text { and } i \text { is odd } \\ n+m+\frac{n-i+1}{2}, 1 \leq i \leq n \text { and } i \text { is even }\end{array}\right.$

To prove this labeling is an edge trimagic total labeling.

Consider the edges $\mathrm{v}_{1} \mathrm{u}_{\mathrm{i}}, 1 \leq \mathrm{i} \leq \mathrm{n}$.

For odd $\mathrm{i}, \mathrm{f}\left(\mathrm{v}_{1}\right)+\mathrm{f}\left(\mathrm{v}_{1} \mathrm{u}_{\mathrm{i}}\right)+\mathrm{f}\left(\mathrm{u}_{\mathrm{i}}\right)=1+2 \mathrm{n}+\mathrm{m}+1-\frac{\mathrm{i}+1}{2}+\mathrm{m}+\frac{\mathrm{i}+1}{2}=2 \mathrm{n}+2 \mathrm{~m}+2=\lambda_{1}$.

For even $\mathrm{i}, \mathrm{f}\left(\mathrm{v}_{1}\right)+\mathrm{f}\left(\mathrm{v}_{1} \mathrm{u}_{\mathrm{i}}\right)+\mathrm{f}\left(\mathrm{u}_{\mathrm{i}}\right)=1+\mathrm{n}+\mathrm{m}+\frac{\mathrm{n}-\mathrm{i}+1}{2}+\mathrm{m}+\frac{\mathrm{n}+\mathrm{i}+1}{2}=2 \mathrm{n}+2 \mathrm{~m}+2=\lambda_{1}$.

Consider the edges $\mathrm{u}_{\mathrm{i}} \mathrm{u}_{\mathrm{i}+1}, 1 \leq \mathrm{i} \leq \mathrm{n}-1$.

For odd $\mathrm{i}, \mathrm{f}\left(\mathrm{u}_{\mathrm{i}}\right)+\mathrm{f}\left(\mathrm{u}_{\mathrm{i}} \mathrm{u}_{\mathrm{i}+1}\right)+\mathrm{f}\left(\mathrm{u}_{\mathrm{i}+1}\right)=\mathrm{m}+\frac{\mathrm{i}+1}{2}+3 \mathrm{n}+\mathrm{m}-\mathrm{i}+\mathrm{m}+\frac{\mathrm{n}+\mathrm{i}+2}{2}=\frac{7 \mathrm{n}+6 \mathrm{~m}+3}{2}=\lambda_{2}$. 


\section{C.Jayasekaran and J.Little Flower}

For even $i, f\left(u_{i}\right)+f\left(u_{i} u_{i+1}\right)+f\left(u_{i+1}\right)=m+\frac{n+i+1}{2}+3 n+m-i+m+\frac{i+2}{2}=\frac{7 n+6 m+3}{2}=\lambda_{2}$.

Consider the edges $\mathrm{v}_{\mathrm{j}} \mathrm{v}_{\mathrm{j}+1}, 1 \leq \mathrm{j} \leq \mathrm{m}-1$.

For odd $j, f\left(v_{j}\right)+f\left(v_{j} v_{j+1}\right)+f\left(v_{j+1}\right)=\frac{j+1}{2}+3 n+2 m-j-1+\frac{m+j+1}{2}=\frac{6 n+5 m}{2}=\lambda_{3}$.

For even $j, f\left(v_{j}\right)+f\left(v_{j} v_{j+1}\right)+f\left(v_{j+1}\right)=\frac{m+j}{2}+3 n+2 m-j-1+\frac{j+2}{2}=\frac{6 n+5 m}{2}=\lambda_{3}$.

Hence for edge $u v \in E, f(u)+f(u v)+f(v)$ yields any one of the magic constants $\lambda_{1}=$ $2 n+2 m+2, \lambda_{2}=\frac{7 n+6 m+3}{2}$ and $\lambda_{3}=\frac{6 n+5 m}{2}$. Therefore the umbrella $U_{n, m}$ is an edge trimagic for $n$ is odd and $m$ is even.

Case 3. $\mathrm{n}$ is even and $\mathrm{m}$ is odd

Define a bijection $\mathrm{f}: \mathrm{V} \cup \mathrm{E} \rightarrow\{1,2, \ldots, 3 \mathrm{n}+2 \mathrm{~m}-2\}$ such that

$f\left(u_{i}\right)=\left\{\begin{array}{l}m+\frac{i+1}{2}, 1 \leq \mathrm{i} \leq \mathrm{n} \text { and } \mathrm{i} \text { is odd } \\ \mathrm{m}+\frac{\mathrm{n}+\mathrm{i}}{2}, 1 \leq \mathrm{i} \leq \mathrm{n} \text { and } \mathrm{i} \text { is even }\end{array}\right.$

$f\left(v_{j}\right)=\left\{\begin{array}{l}\frac{j+1}{2}, 1 \leq j \leq m \text { and } j \text { is odd } \\ \frac{m+j+1}{2}, 1 \leq j \leq m \text { and } j \text { is even }\end{array}\right.$

$\mathrm{f}\left(\mathrm{u}_{\mathrm{i}} \mathrm{u}_{\mathrm{i}+1}\right)=3 \mathrm{n}+\mathrm{m}-\mathrm{i}, 1 \leq \mathrm{i} \leq \mathrm{n}-1 ; \mathrm{f}\left(\mathrm{v}_{\mathrm{j}} \mathrm{v}_{\mathrm{j}+1}\right)=3 \mathrm{n}+2 \mathrm{~m}-\mathrm{j}-1,1 \leq \mathrm{j} \leq \mathrm{m}-1$ and

$f\left(v_{1} u_{i}\right)=\left\{\begin{array}{l}2 n+m+1-\frac{i+1}{2}, i \text { is odd } \\ n+m+\frac{n-i+2}{2}, i \text { is even }\end{array}\right.$

To prove this labeling is an edge trimagic total labeling.

Consider the edges $\mathrm{v}_{1} \mathrm{u}_{\mathrm{i}}, 1 \leq \mathrm{i} \leq \mathrm{n}$.

For odd $i, f\left(v_{1}\right)+f\left(v_{1} u_{i}\right)+f\left(u_{i}\right)=1+2 n+m+1-\frac{i+1}{2}+m+\frac{i+1}{2}=2 n+2 m+2=\lambda_{1}$.

For even $\mathrm{i}, \mathrm{f}\left(\mathrm{v}_{1}\right)+\mathrm{f}\left(\mathrm{v}_{1} \mathrm{u}_{\mathrm{i}}\right)+\mathrm{f}\left(\mathrm{u}_{\mathrm{i}}\right)=1+\mathrm{n}+\mathrm{m}+\frac{\mathrm{n}-\mathrm{i}+2}{2}+\mathrm{m}+\frac{\mathrm{n}+\mathrm{i}}{2}=2 \mathrm{n}+2 \mathrm{~m}+2=\lambda_{1}$.

Consider the edges $\mathrm{u}_{\mathrm{i}} \mathrm{u}_{\mathrm{i}+1}, 1 \leq \mathrm{i} \leq \mathrm{n}-1$.

For odd $\mathrm{i}, \mathrm{f}\left(\mathrm{u}_{\mathrm{i}}\right)+\mathrm{f}\left(\mathrm{u}_{\mathrm{i}} \mathrm{u}_{\mathrm{i}+1}\right)+\mathrm{f}\left(\mathrm{u}_{\mathrm{i}+1}\right)=\mathrm{m}+\frac{\mathrm{i}+1}{2}+3 \mathrm{n}+\mathrm{m}-\mathrm{i}+\mathrm{m}+\frac{\mathrm{n}+\mathrm{i}+1}{2}=\frac{7 \mathrm{n}+6 \mathrm{~m}+2}{2}=\lambda_{2}$. 
On Edge Trimagic Labeling of Umbrella, Dumb Bell and Circular Ladder Graphs

For even $i, f\left(u_{i}\right)+f\left(u_{i} u_{i+1}\right)+f\left(u_{i+1}\right)=m+\frac{n+i}{2}+3 n+m-i+m+\frac{i+2}{2}=\frac{7 n+6 m+2}{2}=\lambda_{2}$.

Consider the edges $\mathrm{v}_{\mathrm{j}} \mathrm{v}_{\mathrm{j}+1}, 1 \leq \mathrm{j} \leq \mathrm{m}-1$.

For odd $j, f\left(v_{j}\right)+f\left(v_{j} v_{j+1}\right)+f\left(v_{j+1}\right)=\frac{j+1}{2}+3 n+2 m-j-1+\frac{m+j+2}{2}=\frac{6 n+5 m+1}{2}=\lambda_{3}$.

For even $\mathrm{j}, \mathrm{f}\left(\mathrm{v}_{\mathrm{j}}\right)+\mathrm{f}\left(\mathrm{v}_{\mathrm{j}} \mathrm{v}_{\mathrm{j}+1}\right)+\mathrm{f}\left(\mathrm{v}_{\mathrm{j}+1}\right)=\frac{\mathrm{m}+\mathrm{j}+1}{2}+3 \mathrm{n}+2 \mathrm{~m}-\mathrm{j}-1+\frac{\mathrm{j}+2}{2}=\frac{6 \mathrm{n}+5 \mathrm{~m}+1}{2}=\lambda_{3}$.

Hence for edge $u v \in E, f(u)+f(u v)+f(v)$ yields any one of the magic constants $\lambda_{1}=$ $2 n+2 m+2, \lambda_{2}=\frac{7 n+6 m+2}{2}$ and $\lambda_{3}=\frac{6 n+5 m+1}{2}$. Therefore the umbrella $U_{n, m}$ is an edge trimagic for $\mathrm{n}$ is even and $\mathrm{m}$ is odd.

Case 4. Both $\mathrm{n}$ and $\mathrm{m}$ are even

Define a bijection $\mathrm{f}: \mathrm{V} \cup \mathrm{E} \rightarrow\{1,2, \ldots, 3 \mathrm{n}+2 \mathrm{~m}-2\}$ such that $\mathrm{f}\left(\mathrm{u}_{\mathrm{i}}\right)=\left\{\begin{array}{l}\mathrm{m}+\frac{\mathrm{i}+1}{2}, 1 \leq \mathrm{i} \leq \mathrm{n} \text { and } \mathrm{i} \text { is odd } \\ \mathrm{m}+\frac{\mathrm{n}+\mathrm{i}}{2}, 1 \leq \mathrm{i} \leq \mathrm{n} \text { and } \mathrm{i} \text { is even }\end{array}\right.$

$f\left(v_{j}\right)=\left\{\begin{array}{l}\frac{j+1}{2}, 1 \leq j \leq m \text { and } j \text { is odd } \\ \frac{m+j}{2}, 1 \leq j \leq m \text { and } j \text { is even }\end{array}\right.$

$\mathrm{f}\left(\mathrm{u}_{\mathrm{i}} \mathrm{u}_{\mathrm{i}+1}\right)=3 \mathrm{n}+\mathrm{m}-\mathrm{i}, 1 \leq \mathrm{i} \leq \mathrm{n}-1 ; \mathrm{f}\left(\mathrm{v}_{\mathrm{j}} \mathrm{v}_{\mathrm{j}+1}\right)=3 \mathrm{n}+2 \mathrm{~m}-\mathrm{j}-1,1 \leq \mathrm{j} \leq \mathrm{m}-1$ and

$f\left(v_{1} u_{i}\right)=\left\{\begin{array}{l}2 n+m+1-\frac{i+1}{2}, 1 \leq i \leq n \text { and } i \text { is odd } \\ 2 n+m+1-\frac{n+i}{2}, 1 \leq i \leq n \text { and } i \text { is even }\end{array}\right.$

To prove this labeling is an edge trimagic total labeling.

Consider the edges $\mathrm{v}_{1} \mathrm{u}_{\mathrm{i}}, 1 \leq \mathrm{i} \leq \mathrm{n}$.

For odd $i, f\left(v_{1}\right)+f\left(v_{1} u_{i}\right)+f\left(u_{i}\right)=1+2 n+m+1-\frac{i+1}{2}+m+\frac{i+1}{2}=2 n+2 m+2=\lambda_{1}$.

For even $i, f\left(v_{1}\right)+f\left(v_{1} u_{i}\right)+f\left(u_{i}\right)=1+2 n+m+1-\frac{n+i}{2}+m+\frac{n+i}{2}=2 n+2 m+2=\lambda_{1}$.

Consider the edges $\mathrm{u}_{\mathrm{i}} \mathrm{u}_{\mathrm{i}+1}, 1 \leq \mathrm{i} \leq \mathrm{n}-1$.

For odd $\mathrm{i}, \mathrm{f}\left(\mathrm{u}_{\mathrm{i}}\right)+\mathrm{f}\left(\mathrm{u}_{\mathrm{i}} \mathrm{u}_{\mathrm{i}+1}\right)+\mathrm{f}\left(\mathrm{u}_{\mathrm{i}+1}\right)=\mathrm{m}+\frac{\mathrm{i}+1}{2}+3 \mathrm{n}+\mathrm{m}-\mathrm{i}+\mathrm{m}+\frac{\mathrm{n}+\mathrm{i}+1}{2}=\frac{7 \mathrm{n}+6 \mathrm{~m}+2}{2}=\lambda_{2}$. 


\section{C.Jayasekaran and J.Little Flower}

For even $\mathrm{i}, \mathrm{f}\left(\mathrm{u}_{\mathrm{i}}\right)+\mathrm{f}\left(\mathrm{u}_{\mathrm{i}} \mathrm{u}_{\mathrm{i}+1}\right)+\mathrm{f}\left(\mathrm{u}_{\mathrm{i}+1}\right)=\mathrm{m}+\frac{\mathrm{n}+\mathrm{i}}{2}+3 \mathrm{n}+\mathrm{m}-\mathrm{i}+\mathrm{m}+\frac{\mathrm{i}+2}{2}=\frac{7 \mathrm{n}+6 \mathrm{~m}+2}{2}=\lambda_{2}$.

Consider the edges $\mathrm{v}_{\mathrm{j}} \mathrm{v}_{\mathrm{j}+1}, 1 \leq \mathrm{j} \leq \mathrm{m}-1$.

For odd $j, f\left(v_{j}\right)+f\left(v_{j} v_{j+1}\right)+f\left(v_{j+1}\right)=\frac{j+1}{2}+3 n+2 m-j-1+\frac{m+j+1}{2}=\frac{6 n+5 m}{2}=\lambda_{3}$.

For even $j, f\left(v_{j}\right)+f\left(v_{j} v_{j+1}\right)+f\left(v_{j+1}\right)=\frac{m+j}{2}+3 n+2 m-j-1+\frac{j+2}{2}=\frac{6 n+5 m}{2}=\lambda_{3}$.

Hence for edge $u v \in E, f(u)+f(u v)+f(v)$ yields any one of the magic constants $\lambda_{1}=$ $2 n+2 m+2, \lambda_{2}=\frac{7 n+6 m+2}{2}$ and $\lambda_{3}=\frac{6 n+5 m}{2}$. Therefore the umbrella $U_{n, m}$ is an edge trimagic for both even $\mathrm{n}$ and $\mathrm{m}$.

Corollary 2.2. The umbrella $U_{n, m}$ is a super edge trimagic total labeling for all $n$.

Proof: We proved that the umbrella $\mathrm{U}_{\mathrm{n}, \mathrm{m}}$ is an edge trimagic total graph for all $\mathrm{n}$ with $\mathrm{n}+\mathrm{m}$ vertices. The labeling given in Theorem 2.1 is as follows:

For odd $\mathrm{n}$ and odd $\mathrm{m}$,

$f\left(u_{i}\right)=\left\{\begin{array}{l}m+\frac{i+1}{2}, 1 \leq \mathrm{i} \leq \mathrm{n} \text { and } \mathrm{i} \text { is odd } \\ \mathrm{m}+\frac{\mathrm{n}+\mathrm{i}+1}{2}, 1 \leq \mathrm{i} \leq \mathrm{n} \text { and } \mathrm{i} \text { is even }\end{array}\right.$

$f\left(v_{j}\right)=\left\{\begin{array}{l}\frac{j+1}{2}, 1 \leq j \leq m \text { and } j \text { is odd } \\ \frac{m+j+1}{2}, 1 \leq j \leq m \text { and } j \text { is even }\end{array}\right.$

For odd $\mathrm{n}$ and even $\mathrm{m}$,

$$
\begin{aligned}
& f\left(u_{i}\right)=\left\{\begin{array}{l}
m+\frac{i+1}{2}, 1 \leq i \leq n \text { and } i \text { is odd } \\
m+\frac{n+i+1}{2}, 1 \leq i \leq n \text { and } i \text { is even }
\end{array}\right. \\
& f\left(v_{j}\right)=\left\{\begin{array}{l}
\frac{j+1}{2}, 1 \leq j \leq m \text { and } j \text { is odd } \\
\frac{m+j}{2}, 1 \leq j \leq m \text { and } j \text { is even }
\end{array}\right.
\end{aligned}
$$

For even $\mathrm{n}$ and odd $\mathrm{m}$,

$$
f\left(u_{i}\right)=\left\{\begin{array}{l}
m+\frac{i+1}{2}, 1 \leq \mathrm{i} \leq \mathrm{n} \text { and } \mathrm{i} \text { is odd } \\
\mathrm{m}+\frac{\mathrm{n}+\mathrm{i}}{2}, 1 \leq \mathrm{i} \leq \mathrm{n} \text { and } \mathrm{i} \text { is even }
\end{array}\right.
$$


On Edge Trimagic Labeling of Umbrella, Dumb Bell and Circular Ladder Graphs $f\left(v_{j}\right)=\left\{\begin{array}{l}\frac{j+1}{2}, 1 \leq j \leq m \text { and } j \text { is odd } \\ \frac{m+j+1}{2}, 1 \leq j \leq m \text { and } j \text { is even }\end{array}\right.$

For even $\mathrm{n}$ and $\mathrm{m}$,

$f\left(u_{i}\right)=\left\{\begin{array}{l}m+\frac{i+1}{2}, 1 \leq i \leq n \text { and } i \text { is odd } \\ m+\frac{n+i}{2}, 1 \leq i \leq n \text { and } i \text { is even }\end{array} \quad f\left(v_{j}\right)=\left\{\begin{array}{l}\frac{j+1}{2}, 1 \leq j \leq m \text { and } j \text { is odd } \\ \frac{m+j}{2}, 1 \leq j \leq m \text { and jis even }\end{array}\right.\right.$

Hence the $n+m$ vertices get labels $1,2, \ldots, n+m$. Therefore, the umberlla $U_{n, m}$ is a super edge trimagic total labeling graph for all $\mathrm{n}$.

Example 2.3. An edge trimagic total labeling of the Umbrella $\mathrm{U}_{5,3} ; \mathrm{U}_{5,4} ; \mathrm{U}_{6,5}$ and $\mathrm{U}_{4,6}$ are given in Figure1, Figure 2, Figure 3 and Figure 4 respectively.

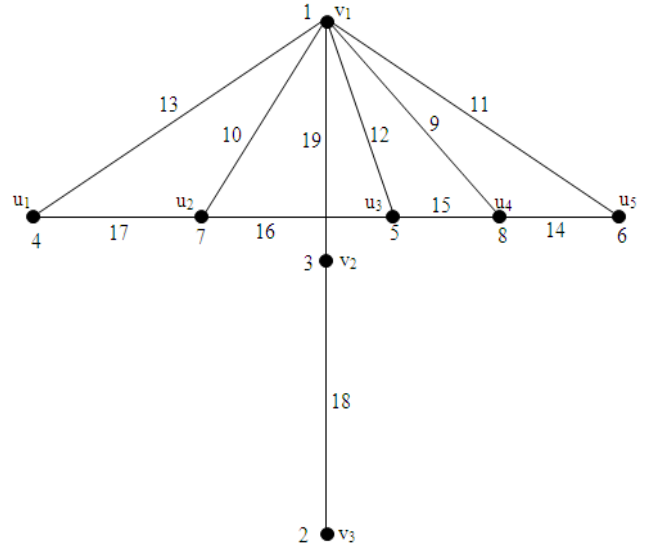

Figure 1: $U_{5,3}$ with $\lambda_{1}=18, \lambda_{2}=28$ and $\lambda_{3}=23$

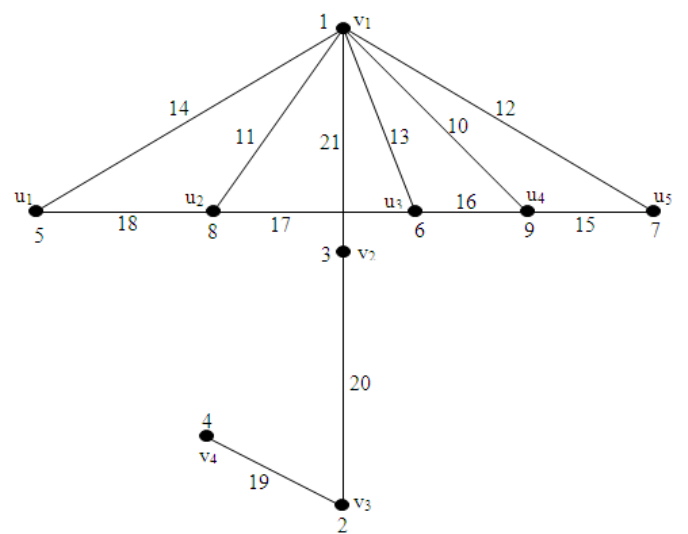

Figure 2: $U_{5,4}$ with $\lambda_{1}=20, \lambda_{2}=31$ and $\lambda_{3}=25$ 


\section{C.Jayasekaran and J.Little Flower}

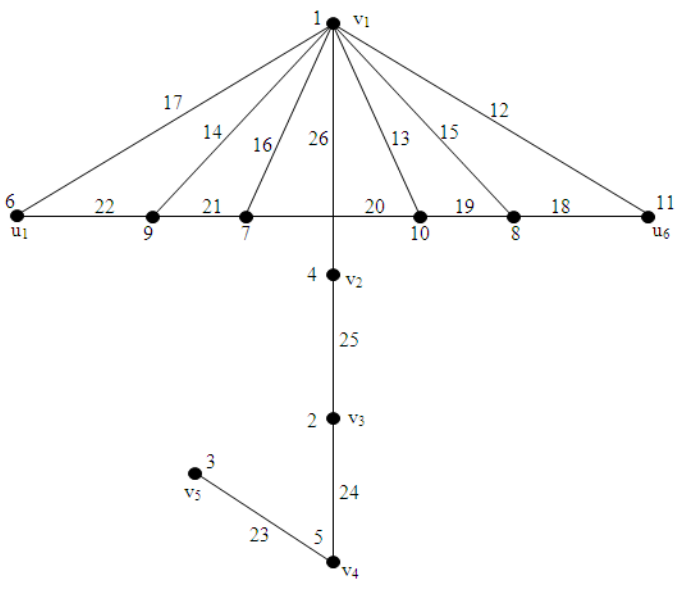

Figure 3: $\mathrm{U}_{6,5}$ with $\lambda_{1}=24, \lambda_{2}=37$ and $\lambda_{3}=31$

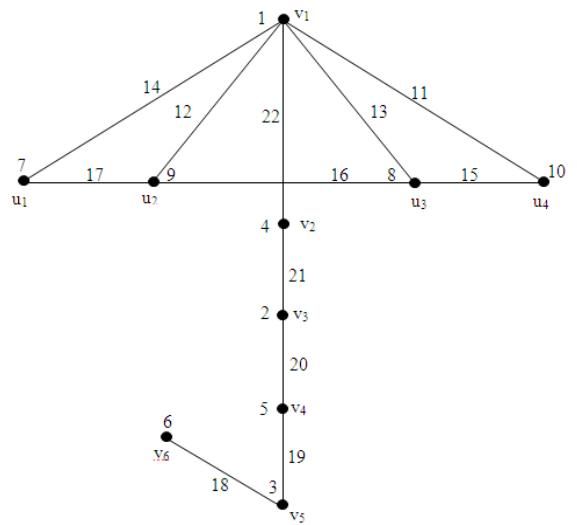

Figure 4. $U_{4,6}$ with $\lambda_{1}=22, \lambda_{2}=33$ and $\lambda_{3}=27$

Theorem 2.4. The Dumbbell $\mathrm{Db} b_{\mathrm{n}}$ is an edge trimagic total labeling for all $\mathrm{n}$.

Proof: Let $V=\left\{u_{i}, v_{i} / 1 \leq i \leq n\right\}$ be the vertex set and $E=\left\{u_{i} u_{i+1}, v_{i} v_{i+1} / 1 \leq i \leq n-\right.$ $1\} \cup\left\{u_{1} u_{n}, v_{1} v_{n}\right\} \cup\left\{u_{1} v_{1}\right\}$ be the edge set of the graph $D b_{n}$. Then $D b_{n}$ has $2 n$ vertices and $2 n+1$ edges.

Case $1 . n$ is even

Define a bijection $\mathrm{f}: \mathrm{V} \cup \mathrm{E} \rightarrow\{1,2, \ldots, 4 \mathrm{n}+1\}$ such that $\mathrm{f}\left(\mathrm{u}_{\mathrm{i}}\right)=2 \mathrm{i}-1,1 \leq \mathrm{i} \leq \mathrm{n}$; $\mathrm{f}\left(\mathrm{v}_{\mathrm{i}}\right)=2 \mathrm{i}, 1 \leq \mathrm{i} \leq \mathrm{n} ;$

$f\left(u_{i} u_{i+1}\right)=\left\{\begin{array}{l}4 n-4 i+3,1 \leq i \leq \frac{n}{2} \\ 6 n-4 i, \frac{n}{2}+1 \leq i \leq n-1\end{array}\right.$ 
On Edge Trimagic Labeling of Umbrella, Dumb Bell and Circular Ladder Graphs $f\left(v_{i} v_{i+1}\right)=\left\{\begin{array}{l}4 n-4 i+1,1 \leq i \leq \frac{n}{2} \\ 6 n-4 i-2, \frac{n}{2}+1 \leq i \leq n-1\end{array}\right.$

$\mathrm{f}\left(\mathrm{u}_{1} \mathrm{v}_{1}\right)=4 \mathrm{n}+1 ; \mathrm{f}\left(\mathrm{u}_{1} \mathrm{u}_{\mathrm{n}}\right)=4 \mathrm{n} ; \mathrm{f}\left(\mathrm{v}_{1} \mathrm{v}_{\mathrm{n}}\right)=4 \mathrm{n}-2$.

To prove this labeling is an edge trimagic total labeling.

For the edges $u_{i} u_{i+1}, 1 \leq i \leq \frac{n}{2}, f\left(u_{i}\right)+f\left(u_{i} u_{i+1}\right)+f\left(u_{i+1}\right)=2 i-1+4 n-4 i+3+2 i+1=4 n+3=\lambda_{1}$.

For the edges $v_{i} v_{i+1}, 1 \leq i \leq \frac{n}{2}, f\left(v_{i}\right)+f\left(v_{i} v_{i+1}\right)+f\left(v_{i+1}\right)=2 i+4 n-4 i+1+2 i+2=4 n+3=\lambda_{1}$.

For the edge $u_{1} v_{1}, f\left(u_{1}\right)+f\left(u_{1} v_{1}\right)+f\left(v_{1}\right)=1+4 n+1+2=4 n+4=\lambda_{2}$.

For the edges $u_{i} u_{i+1}, \frac{n}{2}+1 \leq i \leq n-1, f\left(u_{i}\right)+f\left(u_{i} u_{i+1}\right)+f\left(u_{i+1}\right)=2 i-1+6 n-4 i+2 i+1=6 n=\lambda_{3}$.

For the edges $v_{i} v_{i+1}, \frac{n}{2}+1 \leq i \leq n-1, f\left(v_{i}\right)+f\left(v_{i} v_{i+1}\right)+f\left(v_{i+1}\right)=2 i+6 n-4 i-2+2 i+2=6 n=\lambda_{3}$.

For the edge $u_{1} u_{n}, f\left(u_{1}\right)+f\left(u_{1} u_{n}\right)+f\left(u_{n}\right)=1+4 n+2 n-1=6 n=\lambda_{3}$.

For the edge $v_{1} v_{n}, f\left(v_{1}\right)+f\left(v_{1} v_{n}\right)+f\left(v_{n}\right)=2+4 n-2+2 n=6 n=\lambda_{3}$.

Hence for each edge $u v \in E, f(u)+f(u v)+f(v)$ yields any one of the magic constants $\lambda_{1}=4 n+3 ; \lambda_{2}=4 n+4$ and $\lambda_{3}=6 n$. Therefore the Dumbbell graph $D b_{n}$ is an edge trimagic for even $\mathrm{n}$.

Case 2. $\mathrm{n}$ is odd

Define a bijection $\mathrm{f}: \mathrm{V} \cup \mathrm{E} \rightarrow\{1$
$\mathrm{f}\left(\mathrm{u}_{\mathrm{i}}\right)=\left\{\begin{array}{l}\frac{\mathrm{i}+1}{2}, 1 \leq \mathrm{i} \leq \mathrm{n} \text { and } \mathrm{i} \text { is odd } \\ \frac{\mathrm{n}+\mathrm{i}+1}{2}, 1 \leq \mathrm{i} \leq \mathrm{n} \text { and } \mathrm{i} \text { is even }\end{array}\right.$
$\mathrm{f}\left(\mathrm{v}_{\mathrm{i}}\right)=\left\{\begin{array}{l}\frac{2 \mathrm{n}+\mathrm{i}+1}{2}, 1 \leq \mathrm{i} \leq \mathrm{n} \text { and } \mathrm{i} \text { is odd } \\ \frac{3 \mathrm{n}+\mathrm{i}+1}{2}, 1 \leq \mathrm{i} \leq \mathrm{n} \text { and } \mathrm{i} \text { is even }\end{array}\right.$

$\mathrm{f}\left(\mathrm{u}_{\mathrm{i}} \mathrm{u}_{\mathrm{i}+1}\right)=3 \mathrm{n}-\mathrm{i}, 1 \leq \mathrm{i} \leq \mathrm{n}-1 ; \mathrm{f}\left(\mathrm{u}_{1} \mathrm{u}_{\mathrm{n}}\right)=3 \mathrm{n} ; \mathrm{f}\left(\mathrm{v}_{\mathrm{i}} \mathrm{v}_{\mathrm{i}+1}\right)=4 \mathrm{n}-\mathrm{i}, 1 \leq \mathrm{i} \leq \mathrm{n}-1 ; \mathrm{f}\left(\mathrm{v}_{1} \mathrm{v}_{\mathrm{n}}\right)=4 \mathrm{n}$ and $\mathrm{f}\left(\mathrm{u}_{1} \mathrm{v}_{1}\right)=4 \mathrm{n}+1$.

To prove this labeling is an edge trimagic total labeling.

Consider the edges $\mathrm{u}_{\mathrm{i}} \mathrm{u}_{\mathrm{i}+1}, 1 \leq \mathrm{i} \leq \mathrm{n}-1$.

For odd $i, f\left(u_{i}\right)+f\left(u_{i} u_{i+1}\right)+f\left(u_{i+1}\right)=\frac{i+1}{2}+3 n-i+\frac{n+i+2}{2}=\frac{7 n+3}{2}=\lambda_{1}$.

For even $i, f\left(u_{i}\right)+f\left(u_{i} u_{i+1}\right)+f\left(u_{i+1}\right)=\frac{n+i+1}{2}+3 n-i+\frac{i+2}{2}=\frac{7 n+3}{2}=\lambda_{1}$. 


\section{C.Jayasekaran and J.Little Flower}

For the edge $u_{1} u_{n}, f\left(u_{1}\right)+f\left(u_{1} u_{n}\right)+f\left(u_{n}\right)=1+3 n+\frac{n+1}{2}=\frac{7 n+3}{2}=\lambda_{1}$.

For the edge $u_{1} v_{1}, f\left(u_{1}\right)+f\left(u_{1} v_{1}\right)+f\left(v_{1}\right)=1+4 n+1+n+1=5 n+3=\lambda_{2}$.

Consider the edges $\mathrm{v}_{\mathrm{i}} \mathrm{v}_{\mathrm{i}+1}, 1 \leq \mathrm{i} \leq \mathrm{n}-1$.

For odd $\mathrm{i}, \mathrm{f}\left(\mathrm{v}_{\mathrm{i}}\right)+\mathrm{f}\left(\mathrm{v}_{\mathrm{i}} \mathrm{v}_{\mathrm{i}+1}\right)+\mathrm{f}\left(\mathrm{v}_{\mathrm{i}+1}\right)=\frac{2 \mathrm{n}+\mathrm{i}+1}{2}+4 \mathrm{n}-\mathrm{i}+\frac{3 \mathrm{n}+\mathrm{i}+2}{2}=\frac{13 \mathrm{n}+3}{2}=\lambda_{3}$.

For even i, $f\left(v_{i}\right)+f\left(v_{i} v_{i+1}\right)+f\left(v_{i+1}\right)=\frac{3 n+i+1}{2}+4 n-i+n+\frac{i+2}{2}=\frac{13 n+3}{2}=\lambda_{3}$.

For the edge $v_{1} v_{n}, f\left(v_{1}\right)+f\left(v_{1} v_{n}\right)+f\left(v_{n}\right)=n+1+4 n+\frac{3 n+1}{2}=\frac{13 n+3}{2}=\lambda_{3}$.

Hence for each edge $u v \in E, f(u)+f(u v)+f(v)$ yields any one of the magic constants $\lambda_{1}=\frac{7 n+3}{2}, \lambda_{2}=5 n+3$ and $\lambda_{3}=\frac{13 n+3}{2}$. Therefore the dumbbell graph $D b_{n}$ is an edge trimagic for odd $\mathrm{n}$. From cases (1) and (2), the Dumbbell $\mathrm{Db}_{\mathrm{n}}$ is an edge Trimagic total labeling for all $\mathrm{n}$.

Corollary 2.5. The Dumbbell $\mathrm{Db}_{\mathrm{n}}$ is a super edge trimagic total labeling for all $\mathrm{n}$.

Proof: We proved that the Dumbbell $\mathrm{Db}_{\mathrm{n}}$ is an edge trimagic total graph for all $\mathrm{n}$ with $2 \mathrm{n}$ vertices. The labeling given in Theorem 2.4 is as follows:

For even $\mathrm{n}, \mathrm{f}\left(\mathrm{u}_{\mathrm{i}}\right)=2 \mathrm{i}-1,1 \leq \mathrm{i} \leq \mathrm{n}$ and $\mathrm{f}\left(\mathrm{v}_{\mathrm{i}}\right)=2 \mathrm{i}, 1 \leq \mathrm{i} \leq \mathrm{n}$.

For odd $n$,

$$
f\left(u_{i}\right)=\left\{\begin{array}{l}
\frac{i+1}{2}, 1 \leq \mathrm{i} \leq \mathrm{n} \text { and } \mathrm{i} \text { is odd } \\
\frac{\mathrm{n}+\mathrm{i}+1}{2}, 1 \leq \mathrm{i} \leq \mathrm{n} \text { and } \mathrm{i} \text { is even }
\end{array}\right.
$$$$
f\left(v_{i}\right)=\left\{\begin{array}{l}
\frac{2 n+i+1}{2}, 1 \leq i \leq n \text { and } i \text { is odd } \\
\frac{3 n+i+1}{2}, 1 \leq \mathrm{i} \leq \mathrm{n} \text { and } \mathrm{i} \text { is even }
\end{array}\right.
$$

Hence the $2 \mathrm{n}$ vertices get labels $1,2, \ldots, 2 \mathrm{n}$. Therefore, the Dumbbell $\mathrm{Db} b_{\mathrm{n}}$ is a super edge trimagic total labeling graph for all $\mathrm{n}$.

Example 2.6. An edge Trimagic total labeling of the Dumbbell $\mathrm{Db}_{8}$; and $\mathrm{Db}_{5}$ are given in figure 5 and figure 6 respectively.

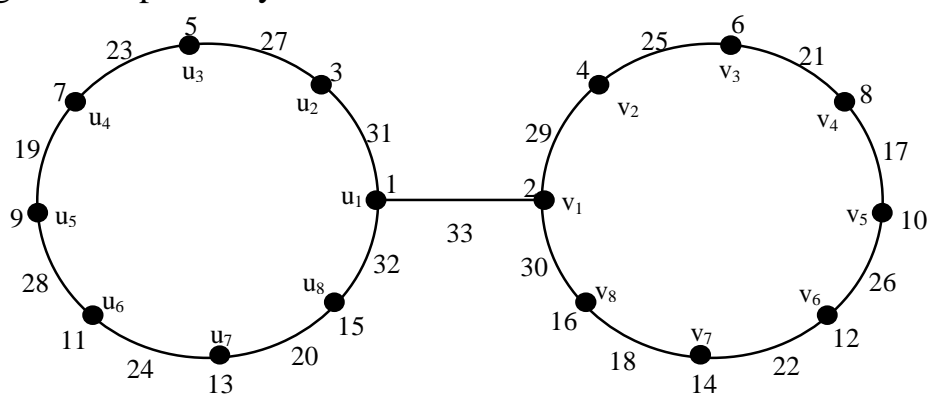

Figure 5: $\mathrm{Db}_{8}$ with $\lambda_{1}=35, \lambda_{2}=36$ and $\lambda_{3}=48$ 
On Edge Trimagic Labeling of Umbrella, Dumb Bell and Circular Ladder Graphs

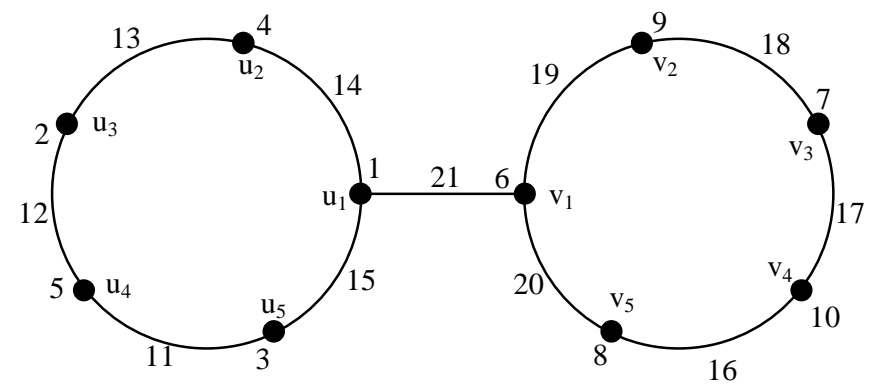

Figure 6: $\mathrm{Db}_{5}$ with $\lambda_{1}=19, \lambda_{2}=28$ and $\lambda_{3}=34$

Theorem 2.7. The circular ladder CL(n) is an edge trimagic total labeling for all $\mathrm{n}$.

Proof: Let $\mathrm{V}=\left\{\mathrm{u}_{\mathrm{i}}, \mathrm{v}_{\mathrm{i}} / 1 \leq \mathrm{i} \leq \mathrm{n}\right\}$ be the vertex set and $\mathrm{E}=\left\{\mathrm{u}_{\mathrm{i}} \mathrm{u}_{\mathrm{i}+1}, \mathrm{v}_{\mathrm{i}} \mathrm{v}_{\mathrm{i}+1} / 1 \leq \mathrm{i} \leq\right.$ $\mathrm{n}-1\} \cup\left\{\mathrm{u}_{\mathrm{i}} \mathrm{v}_{\mathrm{i}} / 1 \leq \mathrm{i} \leq \mathrm{n}\right\} \cup\left\{\mathrm{u}_{1} \mathrm{u}_{\mathrm{n}}, \mathrm{v}_{1} \mathrm{v}_{\mathrm{n}}\right\}$ be the edge set of the graph CL(n). Then CL(n) has $2 n$ vertices and $3 n$ edges.

Case $1 . \mathrm{n}$ is odd

Define a bijection $\mathrm{f}: \mathrm{V} \cup \mathrm{E} \rightarrow\{1,2, \ldots, 5 \mathrm{n}\}$ such that

$\mathrm{f}\left(\mathrm{u}_{\mathrm{i}}\right)=\left\{\begin{array}{l}\mathrm{n}+\frac{\mathrm{n}+\mathrm{i}+2}{2}, 1 \leq \mathrm{i} \leq \mathrm{n}-1 \text { and } \mathrm{i} \text { is odd } \\ \mathrm{n}+\frac{\mathrm{i}+2}{2}, 1 \leq \mathrm{i} \leq \mathrm{n}-1 \text { and } \mathrm{i} \text { is even }\end{array}\right.$

$\mathrm{f}\left(\mathrm{v}_{\mathrm{i}}\right)=\left\{\begin{array}{l}\frac{\mathrm{i}+1}{2}, 1 \leq \mathrm{i} \leq \mathrm{n} \text { and } \mathrm{i} \text { is odd } \\ \frac{\mathrm{n}+\mathrm{i}+1}{2}, 1 \leq \mathrm{i} \leq \mathrm{n} \text { and } \mathrm{i} \text { is even }\end{array}\right.$

$\mathrm{f}\left(\mathrm{u}_{\mathrm{n}}\right)=\mathrm{n}+1 ; \mathrm{f}\left(\mathrm{u}_{\mathrm{i}} \mathrm{u}_{\mathrm{i}+1}\right)=4 \mathrm{n}-\mathrm{i}-1,1 \leq \mathrm{i} \leq \mathrm{n}-2 ; \mathrm{f}\left(\mathrm{u}_{\mathrm{n}} \mathrm{u}_{\mathrm{n}-1}\right)=4 \mathrm{n} ; \mathrm{f}\left(\mathrm{u}_{1} \mathrm{u}_{\mathrm{n}}\right)=4 \mathrm{n}-1 ; \mathrm{f}\left(\mathrm{v}_{\mathrm{i}} \mathrm{v}_{\mathrm{i}+1}\right)=5 \mathrm{n}-\mathrm{i}$, $1 \leq \mathrm{i} \leq \mathrm{n}-1 ; \mathrm{f}\left(\mathrm{v}_{1} \mathrm{v}_{\mathrm{n}}\right)=5 \mathrm{n} ; \mathrm{f}\left(\mathrm{u}_{\mathrm{i}} \mathrm{v}_{\mathrm{i}}\right)=3 \mathrm{n}-\mathrm{i}, 1 \leq \mathrm{i} \leq \mathrm{n}-1$ and $\mathrm{f}\left(\mathrm{u}_{\mathrm{n}} \mathrm{v}_{\mathrm{n}}\right)=3 \mathrm{n}$.

To prove this labeling is an edge trimagic total labeling.

Consider the edges $\mathrm{u}_{\mathrm{i}} \mathrm{u}_{\mathrm{i}+1}, 1 \leq \mathrm{i} \leq \mathrm{n}-2$.

For odd $\mathrm{i}, \mathrm{f}\left(\mathrm{u}_{\mathrm{i}}\right)+\mathrm{f}\left(\mathrm{u}_{\mathrm{i}} \mathrm{u}_{\mathrm{i}+1}\right)+\mathrm{f}\left(\mathrm{u}_{\mathrm{i}+1}\right)=\mathrm{n}+\frac{\mathrm{n}+\mathrm{i}+2}{2}+4 \mathrm{n}-\mathrm{i}-1+\mathrm{n}+\frac{\mathrm{i}+3}{2}=\frac{13 \mathrm{n}+3}{2}=\lambda_{1}$.

For even $i, f\left(u_{i}\right)+f\left(u_{i} u_{i+1}\right)+f\left(u_{i+1}\right)=n+\frac{i+2}{2}+4 n-i-1+n+\frac{n+i+3}{2}=\frac{13 n+3}{2}=\lambda_{1}$.

For the edge $u_{1} u_{n}, f\left(u_{1}\right)+f\left(u_{1} u_{n}\right)+f\left(u_{n}\right)=n+\frac{n+3}{2}+4 n-1+n+1=\frac{13 n+3}{2}=\lambda_{1}$.

For the edge $u_{n-1} u_{n}, f\left(u_{n-1}\right)+f\left(u_{n-1} u_{n}\right)+f\left(u_{n}\right)=n+\frac{n+1}{2}+4 n+n+1=\frac{13 n+3}{2}=\lambda_{1}$.

Consider the edges $\mathrm{u}_{\mathrm{i}} \mathrm{v}_{\mathrm{i}}, 1 \leq \mathrm{i} \leq \mathrm{n}-1$. 


\section{C.Jayasekaran and J.Little Flower}

For odd $i, f\left(u_{i}\right)+f\left(u_{i} v_{i}\right)+f\left(v_{i}\right)=n+\frac{n+i+2}{2}+3 n-i+\frac{i+1}{2}=\frac{9 n+3}{2}=\lambda_{2}$.

For even $\mathrm{i}, \mathrm{f}\left(\mathrm{u}_{\mathrm{i}}\right)+\mathrm{f}\left(\mathrm{u}_{\mathrm{i}} \mathrm{v}_{\mathrm{i}}\right)+\mathrm{f}\left(\mathrm{v}_{\mathrm{i}}\right)=\mathrm{n}+\frac{\mathrm{i}+2}{2}+3 \mathrm{n}-\mathrm{i}+\frac{\mathrm{n}+\mathrm{i}+1}{2}=\frac{9 \mathrm{n}+3}{2}=\lambda_{2}$.

For the edge $u_{n} v_{n}, f\left(u_{n}\right)+f\left(u_{n} v_{n}\right)+f\left(v_{n}\right)=n+1+3 n+\frac{n+1}{2}=\frac{9 n+3}{2}=\lambda_{2}$.

Consider the edges $\mathrm{v}_{\mathrm{i}} \mathrm{v}_{\mathrm{i}+1}, 1 \leq \mathrm{i} \leq \mathrm{n}-1$.

For odd $\mathrm{i}, \mathrm{f}\left(\mathrm{v}_{\mathrm{i}}\right)+\mathrm{f}\left(\mathrm{v}_{\mathrm{i}} \mathrm{v}_{\mathrm{i}+1}\right)+\mathrm{f}\left(\mathrm{v}_{\mathrm{i}+1}\right)=\frac{\mathrm{i}+1}{2}+5 \mathrm{n}-\mathrm{i}+\frac{\mathrm{n}+\mathrm{i}+2}{2}=\frac{11 \mathrm{n}+3}{2}=\lambda_{3}$.

For even $i, f\left(v_{i}\right)+f\left(v_{i} v_{i+1}\right)+f\left(v_{i+1}\right)=\frac{n+i+1}{2}+5 n-i+\frac{i+2}{2}=\frac{11 n+3}{2}=\lambda_{3}$.

For the edge $v_{1} u_{n}, f\left(v_{1}\right)+f\left(v_{1} u_{n}\right)+f\left(u_{n}\right)=1+5 n+\frac{n+1}{2}=\frac{11 n+3}{2}=\lambda_{3}$.

Hence for each edge $u v \in E, f(u)+f(u v)+f(v)$ yields any one of the magic constants $\lambda_{1}=\frac{13 n+3}{2}, \lambda_{2}=\frac{9 n+3}{2}$ and $\lambda_{3}=\frac{11 n+3}{2}$. Therefore the Circular ladder CL(n) is an edge trimagic for odd $n$.

Case 2. $\mathrm{n}$ is even

Define a bijection $\mathrm{f}: \mathrm{V} \cup \mathrm{E} \rightarrow\{1,2, \ldots, 5 \mathrm{n}\}$ such that

$f\left(u_{i}\right)=\left\{\begin{array}{l}n+\frac{i+1}{2}, 1 \leq i \leq n \text { and } i \text { is odd } \\ n+\frac{n+i}{2}, 1 \leq \mathrm{i} \leq \mathrm{n} \text { and } \mathrm{i} \text { is even }\end{array}\right.$

$\mathrm{f}\left(\mathrm{v}_{\mathrm{i}}\right)=\left\{\begin{array}{l}\frac{\mathrm{i}+1}{2}, 1 \leq \mathrm{i} \leq \mathrm{n} \text { and } \mathrm{i} \text { is odd } \\ \frac{\mathrm{n}+\mathrm{i}}{2}, 1 \leq \mathrm{i} \leq \mathrm{n} \text { and } \mathrm{i} \text { is even }\end{array}\right.$

$\mathrm{f}\left(\mathrm{u}_{\mathrm{i}} \mathrm{u}_{\mathrm{i}+1}\right)=3 \mathrm{n}-\mathrm{i}+1,1 \leq \mathrm{i} \leq \mathrm{n}-1 ; \mathrm{f}\left(\mathrm{u}_{1} \mathrm{u}_{\mathrm{n}}\right)=2 \mathrm{n}+1 ; \mathrm{f}\left(\mathrm{v}_{\mathrm{i}} \mathrm{v}_{\mathrm{i}+1}\right)=5 \mathrm{n}-\mathrm{i}+1,1 \leq \mathrm{i} \leq \mathrm{n}-1 ; \mathrm{f}\left(\mathrm{v}_{1} \mathrm{v}_{\mathrm{n}}\right)=$ $4 \mathrm{n}+1 ;$ and $\mathrm{f}\left(\mathrm{u}_{\mathrm{i}} \mathrm{v}_{\mathrm{i}}\right)=4 \mathrm{n}-\mathrm{i}+1,1 \leq \mathrm{i} \leq \mathrm{n}$.

To prove this labeling is an edge trimagic total labeling.

For the edge $v_{1} v_{n}, f\left(v_{1}\right)+f\left(v_{1} v_{n}\right)+f\left(v_{n}\right)=1+4 n+1+n=5 n+2=\lambda_{1}$.

For the edge $u_{1} u_{n}, f\left(u_{1}\right)+f\left(u_{1} u_{n}\right)+f\left(u_{n}\right)=n+1+2 n+1+2 n=5 n+2=\lambda_{1}$.

Consider the edges $u_{i} v_{i}, 1 \leq \mathrm{i} \leq n$.

For odd $i, f\left(u_{i}\right)+f\left(u_{i} v_{i}\right)+f\left(v_{i}\right)=\frac{i+1}{2}+4 n-i+1+n+\frac{i+1}{2}=5 n+2=\lambda_{1}$.

For even $\mathrm{i}, \mathrm{f}\left(\mathrm{u}_{\mathrm{i}}\right)+\mathrm{f}\left(\mathrm{u}_{\mathrm{i}} \mathrm{v}_{\mathrm{i}}\right)+\mathrm{f}\left(\mathrm{v}_{\mathrm{i}}\right)=\frac{\mathrm{n}+\mathrm{i}}{2}+4 \mathrm{n}-\mathrm{i}+1+\mathrm{n}+\frac{\mathrm{n}+\mathrm{i}}{2}=6 \mathrm{n}+1=\lambda_{2}$. 
On Edge Trimagic Labeling of Umbrella, Dumb Bell and Circular Ladder Graphs Consider the edges $\mathrm{u}_{\mathrm{i}} \mathrm{u}_{\mathrm{i}+1}, 1 \leq \mathrm{i} \leq \mathrm{n}-1$.

For odd $\mathrm{i}, \mathrm{f}\left(\mathrm{u}_{\mathrm{i}}\right)+\mathrm{f}\left(\mathrm{u}_{\mathrm{i}} \mathrm{u}_{\mathrm{i}+1}\right)+\mathrm{f}\left(\mathrm{u}_{\mathrm{i}+1}\right)=\mathrm{n}+\frac{\mathrm{i}+1}{2}+3 \mathrm{n}-\mathrm{i}+1+\mathrm{n}+\frac{\mathrm{n}+\mathrm{i}+1}{2}=\frac{11 \mathrm{n}+4}{2}=\lambda_{3}$.

For even $\mathrm{i}, \mathrm{f}\left(\mathrm{u}_{\mathrm{i}}\right)+\mathrm{f}\left(\mathrm{u}_{\mathrm{i}} \mathrm{u}_{\mathrm{i}+1}\right)+\mathrm{f}\left(\mathrm{u}_{\mathrm{i}+1}\right)=\mathrm{n}+\frac{\mathrm{n}+\mathrm{i}}{2}+3 \mathrm{n}-\mathrm{i}+1+\mathrm{n}+\frac{\mathrm{i}+2}{2}=\frac{11 \mathrm{n}+4}{2}=\lambda_{3}$.

Consider the edges $\mathrm{v}_{\mathrm{i}} \mathrm{v}_{\mathrm{i}+1}, 1 \leq \mathrm{i} \leq \mathrm{n}-1$.

For odd $\mathrm{i}, \mathrm{f}\left(\mathrm{v}_{\mathrm{i}}\right)+\mathrm{f}\left(\mathrm{v}_{\mathrm{i}} \mathrm{v}_{\mathrm{i}+1}\right)+\mathrm{f}\left(\mathrm{v}_{\mathrm{i}+1}\right)=\frac{\mathrm{i}+1}{2}+5 \mathrm{n}-\mathrm{i}+1+\frac{\mathrm{n}+\mathrm{i}+1}{2}=\frac{11 \mathrm{n}+4}{2}=\lambda_{3}$.

For even $\mathrm{i}, \mathrm{f}\left(\mathrm{v}_{\mathrm{i}}\right)+\mathrm{f}\left(\mathrm{v}_{\mathrm{i}} \mathrm{v}_{\mathrm{i}+1}\right)+\mathrm{f}\left(\mathrm{v}_{\mathrm{i}+1}\right)=\frac{\mathrm{n}+\mathrm{i}}{2}+5 \mathrm{n}-\mathrm{i}+1+\frac{\mathrm{i}+2}{2}=\frac{11 \mathrm{n}+4}{2}=\lambda_{3}$.

Hence for each edge $u v \in E, f(u)+f(u v)+f(v)$ yields any one of the magic constants $\lambda_{1}=5 n+2, \lambda_{2}=6 n+1$ and $\lambda_{3}=\frac{11 n+4}{2}$. Therefore, the Circular ladder CL(n) is an edge trimagic for even $\mathrm{n}$. Hence by case 1 and case 2, the circular ladder CL(n) is an edge Trimagic total labeling for all $\mathrm{n}$.

Corollary 2.8. The Circular ladder CL(n) is a super edge trimagic total labeling for all $n$. Proof: We proved that the Circular ladder CL(n) is an edge trimagic total graph for all $n$ with $2 \mathrm{n}$ vertices. The labeling given in Theorem 2.7 is as follows:

For odd $n$,

$$
\begin{aligned}
& \mathrm{f}\left(\mathrm{u}_{\mathrm{i}}\right)=\left\{\begin{array}{l}
\mathrm{n}+\frac{\mathrm{n}+\mathrm{i}+2}{2}, 1 \leq \mathrm{i} \leq \mathrm{n}-1 \text { and } \mathrm{i} \text { is odd } \\
\mathrm{n}+\frac{\mathrm{i}+2}{2}, 1 \leq \mathrm{i} \leq \mathrm{n}-1 \text { and } \mathrm{i} \text { is even }
\end{array}\right. \\
& \mathrm{f}\left(\mathrm{v}_{\mathrm{i}}\right)=\left\{\begin{array}{l}
\frac{\mathrm{i}+1}{2}, 1 \leq \mathrm{i} \leq \mathrm{n} \text { and } \mathrm{i} \text { is odd } \\
\frac{\mathrm{n}+\mathrm{i}+1}{2}, 1 \leq \mathrm{i} \leq \mathrm{n} \text { and } \mathrm{i} \text { is even }
\end{array}\right.
\end{aligned}
$$

For even n,

$$
\begin{aligned}
& f\left(u_{i}\right)=\left\{\begin{array}{l}
n+\frac{i+1}{2}, 1 \leq \mathrm{i} \leq \mathrm{n} \text { and } \mathrm{i} \text { is odd } \\
\mathrm{n}+\frac{\mathrm{n}+\mathrm{i}}{2}, 1 \leq \mathrm{i} \leq \mathrm{n} \text { and } \mathrm{i} \text { is even }
\end{array}\right. \\
& \mathrm{f}\left(\mathrm{v}_{\mathrm{i}}\right)=\left\{\begin{array}{l}
\frac{\mathrm{i}+1}{2}, 1 \leq \mathrm{i} \leq \mathrm{n} \text { and } \mathrm{i} \text { is odd } \\
\frac{\mathrm{n}+\mathrm{i}}{2}, 1 \leq \mathrm{i} \leq \mathrm{n} \text { and } \mathrm{i} \text { is even }
\end{array}\right.
\end{aligned}
$$




\section{C.Jayasekaran and J.Little Flower}

Hence the $2 \mathrm{n}$ vertices get labels $1,2, \ldots, 2 \mathrm{n}$. Therefore, the Circular ladder CL(n) is a super edge trimagic total labeling graph for all $\mathrm{n}$.

Example 2.9. An edge Trimagic total labeling of the Circular ladder CL(7) and CL(6) are given in figure 7 and figure 8 respectively

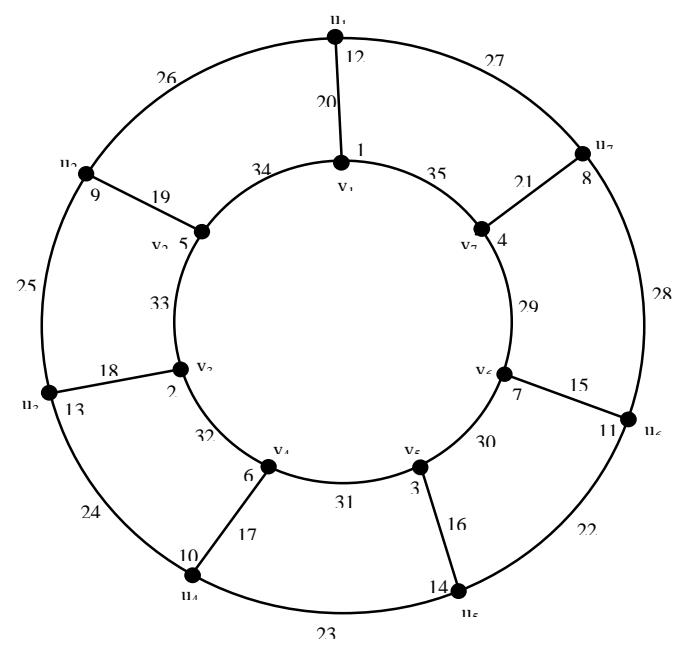

Figure 7: $\operatorname{CL}(7)$ with $\lambda_{1}=47, \lambda_{2}=33$ and $\lambda_{3}=40$

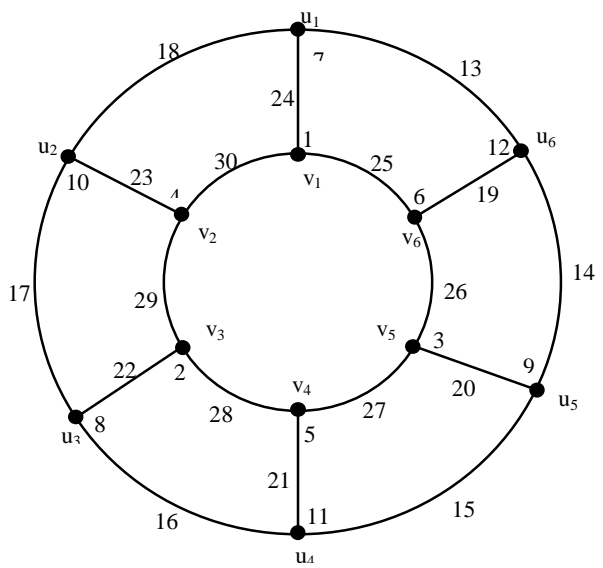

Figure 8: $C L(6)$ with $\lambda_{1}=32, \lambda_{2}=37$ and $\lambda_{3}=35$

\section{Conclusion}

In this paper we have determined the edge trimagic total labeling of the Umbrella, Dumbbell and Circular ladder graphs. Also we have determined the above graphs are super edge Trimagic total labeling.

Acknowledgement. The authors are grateful to the anonymous referee for providing thoughtful comments and valuable suggestions. 
On Edge Trimagic Labeling of Umbrella, Dumb Bell and Circular Ladder Graphs

\section{REFERENCES}

1. S.Babith, A.Amarajothi and J.B.Babujee, Magic and bimagic labeling for disconnected graphs, Intern. J. Mathematics Trends and Technology, 3(2) (2012) 86-90.

2. J.B.Babujee, On edge bimagic labeling, Journal of Combinations Information \& System Sciences, 1-4 (2004) 239-244 .

3. L.Girija and A.Elumalai, Edge magic total labeling of the cycle $\mathrm{C}_{\mathrm{n}}$ with $\mathrm{P}_{3}$ chords, Annals of Pure and Applied Mathematics, 8(2) (2014) 175-181.

4. F.Harary, Graph theory, Narosa Publishing house, New Delhi (2001).

5. I.Rajasingh, B.Rajan and V.Annamma, Total vertex irregularity strength of circular ladder and windmill graphs, International Conference on Mathematical Computer Engineering - ICMCE (2013) 418-423.

6. C.Jayasekaran, M.Regees and C.Davidraj, Edge trimagic labeling of some graphs, Intern. J. Combinatorial Graph Theory and Applications, 6(2) (2013) 175-186.

7. C.Jayasekaran and M.Regees, Edge trimagic in digraphs, Journal of Discrete Mathematical Sciences and Cryptography, 17(4) (2015) 321-335.

8. J.A.Gallian, A dynamic survey of graph labeling, The Electronic Journal of Combinatorics, 16 (2013) \#DS6.

9. A.Kotzing and A.Rosa, Magic valuations of finite graphs, Canad. Math. Bull., 13 (1970) 415-416.

10. R.Ponraj, S.S.Narayanan and A.M.S. Ramasamy, Total mean cordiality of umbrella, butterfly and dumb bell graphs, Jordan Journal of Mathematics and Statistics, 8(1) (2015) 59-77.

11. J.Sedlacek, Problem 27: in Theory of Graphs and its Applications, Proc. Symposium Smolenice, June (1963) 163-167.

12. S.S.Basha, Reverse super edge-magic labeling on W-trees, Intern. Journal of Computer Engineering In Research Trends, 2(11) (2015) 719-721. 